\title{
Senescence is accelerated through donor cell specificity in cloned pigs
}

\author{
HYUN YONG JEON $^{1}$, YEON WOO JEONG ${ }^{1}$, YEON WOOK KIM ${ }^{1}$, YEON IK JEONG ${ }^{1}$, SHAMIM M. HOSSEIN ${ }^{1}$, \\ HYUN YANG $^{2}$, SANG HWAN HYUN ${ }^{1,2}$, EUI-BAE JEUNG ${ }^{2}$ and WOO SUK HWANG ${ }^{1}$ \\ ${ }^{1}$ Sooam Biotech Research Foundation, Guro-gu, Seoul 152-904; ${ }^{2}$ College of Veterinary Medicine, \\ Chungbuk National University, Cheongju, Chungbuk 361-763, Republic of Korea
}

Received February 29, 2012; Accepted April 27, 2012

DOI: $10.3892 /$ ijmm.2012.1003

\begin{abstract}
Animals cloned by somatic cell nuclear transfer (SCNT) sometimes have abnormalities that result in large offspring syndrome or early death during gestation due to respiratory and metabolic defects. We cloned pigs using two sources of donor cells and observed phenotypic anomalies in three pigs cloned from one type of cell, s-pig fetal fibroblasts. These animals had many wrinkles on their faces and bodies and looked older than age-matched normal pigs. We performed the present study to examine whether the wrinkled phenotype in the cloned pigs was due to senescence, a genetic problem with donor specificity, or epigenetic problems with reprogramming. To address this issue, we investigated biomarkers of senescence, including telomere length and the expression of senescence-associated $\beta$-galactosidase (SA- $\beta$-gal), glyceraldehyde phosphate dehydrogenase (GAPDH) and $\beta$-actin. We also assessed the methylation status of euchromatic PRE-1 repetitive sequences and centromeric satellite DNA, and measured the mRNA levels of six imprinted genes, Copg2, Mest, Igf2R, GNAS, SNRPN and Ube3a. The telomeres of the wrinkled cloned pigs were much shorter than those of the normal cloned pigs and age-matched normal pigs. In the wrinkled cloned pigs, SA- $\beta$-gal activity was detected and GAPDH and $\beta$-actin were repressed. The mRNA levels of Mest, GNAS and Ube3a were reduced in the wrinkled cloned pigs, although there was no difference between the normal cloned pigs and normal controls. This gene expression analysis indicates that the wrinkled abnormality of our pigs originates from genetic abnormalities in the donor cells used for SCNT.
\end{abstract}

Correspondence to: Dr Eui-Bae Jeung, Laboratory of Veterinary Biochemistry and Molecular Biology, College of Veterinary Medicine, Chungbuk National University, Cheongju, Chungbuk 361-763, Republic of Korea

E-mail: ebjeung@cbu.ac.kr

Dr Woo Suk Hwang, Sooam Biotech Research Foundation, San 43-41 Oryu-dong, Guro-gu, Seoul 152-904, Republic of Korea E-mail: hwangws@sooam.org

Key words: senescence, cloned pigs, somatic cell nuclear transfer

\section{Introduction}

Despite the successful production of cloned animals, including sheep (1,2), cattle (3-7), goats (8), pigs (9-11) and mice (12-14), somatic cell nuclear transfer (SCNT) is still hampered by extremely low efficiency. Early embryonic and fetal loss, stillbirth, and postnatal loss and phenotypic abnormities are commonly reported $(12,15-18)$. The fetal losses and abnormalities may be associated with abnormal placental development (17). Most cloned cows and mice lost prenatally and postnatally are associated with enlarged and dysfunctional placentas $(17,19)$. It was recently proposed that the high rates of developmental failure and abnormalities may be caused by epigenetic alterations $(20,21)$. After SCNT, the donor nucleus requires epigenetic reprogramming to re-enter a totipotent ground state (22), suggesting that the donor nucleus must cease its own program of gene expression and restore the particular program of embryonic expression necessary for normal development. If the reprogramming process is inefficient, embryogenesis will be abnormal (23). Poor epigenetic reprogramming in early-cleavage embryos results in dysregulation of gene expression and abnormal proteins accumulate that can disrupt normal embryonic or fetal development. Indeed, along with the low survival rate, various disease phenotypes have been observed in cloned animals, including circulatory distress, placental edema, hydrallantois, respiratory problems, immune dysfunction and brain malformation $(17,18,24)$. In theory, therefore, partial reprogramming can result in a range of outcomes, including abnormal phenotypes or lethality at various stages of development.

Epigenetic modifications of the genome include changes in genomic methylation, the acetylation state of histones and the remodeling of chromatin. DNA methylation regulates the function of the genome by affecting tissue-specific gene expression, cell differentiation, genomic imprinting, $\mathrm{X}$ chromosome inactivation, regulation of chromatin structure, carcinogenesis and aging (25). Recently, Kang et al (26) reported that methylation levels of repeated regions and unique sequences were much higher in cloned morulae and blastocysts than in normal embryos and resembled the methylation levels in the donor cell genome. Interphase nuclei in cloned bovine morulae also contain high methylation levels (27), indicating that reprogramming is deficient in most cloned preimplantation embryos and demethylation seems to be particularly inefficient. The 
selective demethylation pattern of developmentally important genes was confirmed in SCNT embryos. Unequal methylation was maintained between the inner cell mass and trophectoderm regions, thereby resulting in placental dysfunction in cloned animals (28).

Genomic imprinting is an epigenetic mechanism by which related genes are inherited in a parental-specific manner (29). Imprinted genes have roles in prenatal growth, development of the germ line and embryo and behavior, as well as being implicated in human disease (30). The evolution of genomic imprinting must have required oocytes to create and maintain the epigenetic asymmetry of donor cells and the importance of the oocyte cytoplasm can be seen in the parent-of-origin effects on interspecific hybrids of the deer mouse (31). The disruption of imprinting may be due to nuclear to nuclearcytoplasmic incompatibility between the nucleus of the donor and the cytoplasm of the recipient in these crosses. Cloning inefficiency also contributes to another incompatibility (32): reduced fetal methylation and repression of ovine IGF2R is associated with fetal overgrowth. Preimplantation embryo procedures may thus be vulnerable to epigenetic alterations in imprinted genes. Kato et al (33) has shown that transplantation of imprint-free primordial germ cell nuclei into oocytes results in embryonic lethality (33) and partially abnormal extraembryonic tissues resulting from the inappropriate silencing or activation of imprinted genes.

Cloning by SCNT is a multiple-step procedure and many factors affect cloning efficiency, such as donor cell type and age, the phase of the cell cycle that the donor cell is in and the SCNT procedure itself. Although the SCNT procedure has been improved, developmental defects are still consistently observed in cloned animals. These defects may be related to methodological faults including squeezing to remove nuclear, activation and fusion, which cause the instability of critical reprogramming.

We have generated three cloned pigs that developed wrinkles on their bodies, a phenotype typical of aged animals, at a relatively young age. Here, we report that this phenotype is due to a genetic abnormality of the donor cells rather than to senescence or epigenetic abnormalities during reprogramming.

\section{Materials and methods}

Preparation of donor cells. Two types of fetal fibroblasts [named s-pig fetal fibroblasts (sPFFs) and w-pig fetal fibroblasts (wPFFs)] were isolated from pig fetuses (on Day 30 of gestation) obtained from a slaughterhouse on different days as it has been described before (34). Briefly, collected fetuses were washed 3 times with $\mathrm{Ca}^{2+}$ - and $\mathrm{Mg}^{2+}$-free phosphate buffered saline (PBS). The head and internal organs were discarded by scooping them out with two watchmaker's forceps. After 2 washes with PBS ( $\mathrm{pH}$ 7.4), the carcass was minced with a surgical blade in a $100 \pi$ culture dish (BectonDickinson, Lincoln Park, NJ). The minced fetal tissues were dissociated in Dulbecco's modified Eagle's medium (DMEM) supplemented with $0.25 \%(\mathrm{w} / \mathrm{v})$ trypsin and $1 \mathrm{mM}$ EDTA for 1-2 $\mathrm{h}$. The trypsinized cells were then washed once in PBS by centrifugation at $300 \mathrm{x}$ g for $10 \mathrm{~min}$ and subsequently seeded into $100-\mathrm{mm}$ culture dishes. The cells were cultured for 6-8 days in DMEM supplemented with $10 \%$ (v/v) fetal bovine serum (FBS), $1 \%$ (v/v) nonessential amino acids and $10 \mu \mathrm{g} / \mathrm{ml}$ penicillin-streptomycin (Sigma-Aldrich, St. Louis, MO) in a humidified atmosphere of 5\% $\mathrm{CO}_{2}$ and $95 \%$ air. After the unattached clumps of cells and explants were removed, the attached cells were further cultured until confluent, subcultured at intervals of 5-7 days by trypsinization and stored after 2 passages in liquid nitrogen at $-196^{\circ} \mathrm{C}$. The freezing medium consisted of $80 \%(\mathrm{v} / \mathrm{v})$ DMEM, 10\% (v/v) dimethylsulfoxide (DMSO; Sigma-Aldrich) and 10\% (v/v) FBS. Before SCNT, frozen fetal fibroblasts (cultured for 3-5 passages) were thawed for 3-5 days in DMEM supplemented with $0.5 \%$ FBS. Individual cells were retrieved from the monolayer by trypsinization for $30 \mathrm{sec}$ and used as donor cells for SCNT.

Production of cloned pigs. The nuclear transfer of donor cells to enucleated porcine oocytes was performed to produce cloned piglets as previously described $(35,36)$. wPFFs produced normal cloned pigs when used as donor nuclei and SPFFs produced the wrinkled cloned pigs. A parentage analysis was performed on the piglets obtained by SCNT and the surrogate recipient females to confirm the identity of the donor cells used for nuclear transfer $(35,36)$. The DNA was extracted from ear punches or tail clippings obtained from each newborn piglet and recipient female. DNA was also extracted from donor cells. Eight porcine DNA microsatellite markers (S0086, S0230, SW902, S0007, S0313, SW61, S0005 and S0164) were used to confirm the genetic identity.

Measurement of telomere length. Telomere length was determined by mean terminal restriction fragment (TRF) length analysis using a Telo TAGGG Telomere Length Assay kit (Roche Diagnostics GmbH, Mannheim, Germany). The genomic DNA $(10 \mu \mathrm{g})$ isolated from donor cells or ear tissues of cloned pigs was digested with the restriction enzymes Hinf I (New England Biolabs, Inc., Beverly, MA) and RsaI (New England Biolabs, Inc.). Undigested or digested genomic DNA samples were fractionated by $0.6 \%$ agarose gel electrophoresis at $30 \mathrm{~V} / \mathrm{cm}$ for $5 \mathrm{~h}$. Gels were denatured, neutralized and transferred to a positively charged nylon membrane (Hybond+; Amersham Pharmacia Biotech, Oakville, Canada). The membranes were prehybridized in $40 \mathrm{ml}$ of DIG Easy Hyb (Roche Diagnostics $\mathrm{GmbH}$ ) for $2 \mathrm{~h}$ at $42^{\circ} \mathrm{C}$ and then hybridized in $10 \mathrm{ml}$ of DIG Easy Hyb containing 50 pmol of an end-labeled telomere-specific probe for $16 \mathrm{~h}$ at $42^{\circ} \mathrm{C}$. Membranes were washed 3 times in $50 \mathrm{ml}$ of $0.5 \mathrm{X}$ standard saline citrate (SSC; $1 \mathrm{X} \mathrm{SSC:} 0.15 \mathrm{M} \mathrm{NaCl}$, $0.015 \mathrm{M}$ sodium citrate) for $15 \mathrm{~min}$ at room temperature. The signals were visualized by chemiluminescence using a DIG Luminescent Detection kit (Roche Diagnostics $\mathrm{GmbH}$ ) and exposed to X-ray film (Hyperfilm; Amersham Pharmacia Biotech). The signals were scanned and analyzed using Gel Doc software (Bio-Rad, Hercules, CA) by taking the mean value of the largest and smallest values.

Cell culture and induction of cellular senescence. SPFFs were routinely cultured until replicative senescence as previously described (38). The slowly growing cultures were replenished with fresh DMEM supplemented with $10 \%$ FBS every 4 days. Confluent sPFFs were exposed to $700 \mu \mathrm{M} \mathrm{H}_{2} \mathrm{O}_{2}$ in DMEM containing $10 \%$ FBS for 5 days as a stressor. After $\mathrm{H}_{2} \mathrm{O}_{2}$ stress for 5 days, the sPFFs were rinsed with PBS and incubated in DMEM with $10 \%$ FBS. 
Table I. Oligo sequences of the primers used for RT-PCR of imprinting genes.

\begin{tabular}{llcr}
\hline Genes & Primer sequences & Tm & $\begin{array}{r}\text { Size } \\
(\mathrm{bp})\end{array}$ \\
\hline COPG2 & 5'-CAAGAAGGACGAGGAGTCTGGTAG-3' & 544 \\
SNRPN & 5'-CACTTGATGCAGCTTCTTGGGCTT-3' & 55 & 380 \\
MEST & 5'-CGGGTTTTGGGTCTGGTGTTG-3' & 60 & 600 \\
& 5'-ATAATGCCTGGAGGTGGGGTTGC-3' & & 582 \\
GNAS1 & 5'-CCTTGATTTCTTAGGCTTTGGCTT-3' & 55 & 818 \\
& 5'-CAGCGTTTTCCTGTACAGCTCCAA-3' & 55 & \\
UBE3A & 5'-GCCAACAAAAAGATCGAGAAGCAG-3' & & 50 \\
& 5'-CCACCTGGAACTTGGTCTCAAAGA-3' & 50 & \\
\hline
\end{tabular}

The primer pairs to detect the mRNAs were first designed from the human and mouse homologous sequences. The PCR products were sequenced, and the resulting pig-specific sequences were used to create the primer pairs employed to measure the transcriptional levels of interested genes.

Galactosidase (Gal) staining in skin tissues. Tissue was collected from the ear skin of cloned pigs, rapidly frozen in liquid nitrogen and mounted in OCT compound (Fisher Scientific). Thin sections $(10 \mu \mathrm{m})$ were cut and mounted onto glass slides. The sections were washed in PBS, fixed for 3-5 min at room temperature in $3 \%$ formaldehyde, washed again and incubated at $37^{\circ} \mathrm{C}$ with fresh senescence associated Gal (SA-Gal) stain solution [1 mg of 5-bromo-4-chloro-3-indoly-D-galactoside (X-Gal)/ml of solution containing $40 \mathrm{mM}$ citric acid/sodium phosphate ( $\mathrm{pH} 6.0), 5 \mathrm{mM}$ potassium ferrocyanide, $5 \mathrm{mM}$ potassium ferricyanide, $150 \mathrm{mM} \mathrm{NaCl}, 2 \mathrm{mM} \mathrm{MgCl}{ }_{2}$. Stain signals were evident after 2-4 h and maximal after 12-16 h.

Bisulfite treatment of genomic DNA. All procedures for genomic DNA preparation have been described previously (37). The genomic DNA was digested with HindIII enzyme in a $20-\mu 1$ reaction volume for $16 \mathrm{~h}$, then denatured with $0.3 \mathrm{~N} \mathrm{NaOH}$. Bisulfite modification (38) was initiated by adding $235 \mu \mathrm{l}$ freshly made $5 \mathrm{M}$ sodium bisulfite ( $\mathrm{pH}$ 5, Sigma) and $13.5 \mu \mathrm{l}$ of $10 \mathrm{mM}$ hydroquinone. The reaction mixture was incubated at $55^{\circ} \mathrm{C}$ for $16 \mathrm{~h}$ in the dark. The bisulfite-treated genomic DNA was recovered using a Wizard DNA purification kit (Promega). Desulfonation was performed by adding $0.3 \mathrm{~N} \mathrm{NaOH}$ and incubating the solution at $37{ }^{\circ} \mathrm{C}$ for $30 \mathrm{~min}$. Following precipitation, the DNA was resuspended in $20 \mu \mathrm{l}$ of distilled water.

Polymerase chain reaction (PCR) amplification, cloning and sequencing. To amplify the satellite region $\left(\mathrm{GenBank} \mathrm{K}^{\mathrm{TM}}\right.$ Z75640) and the PRE-1 sequence (GenBankTM X64127, Y00104 and AJ251914), we performed PCR with ear tissues using $2 \mu \mathrm{l}$ of the bisulfite-converted genomic DNA as a template. The primer set used for the satellite region was 5'TTTGTAGAATGTAGTTTTTAGAAG-3' and 5'-AAAATCT AAACTACCTCTAACTC-3'. The amplification cycle was 45 cycles at $94{ }^{\circ} \mathrm{C}$ for $60 \mathrm{sec}, 55^{\circ} \mathrm{C}$ for $60 \mathrm{sec}$ and $72^{\circ} \mathrm{C}$ for $20 \mathrm{sec}$ and the amplification was finished by incubation at $72^{\circ} \mathrm{C}$ for
10 min. For amplification of the PRE-1 sequence (41), a primer set of 5'-TTAACRAATCCRACTAAAAACCAT A-3' and 5'-GTTGGTTTATMTTAGAGTTATAGTAA-3' was designed. The amplification cycle was 45 cycles at $94^{\circ} \mathrm{C}$ for $60 \mathrm{sec}, 52^{\circ} \mathrm{C}$ for $60 \mathrm{sec}$ and $72^{\circ} \mathrm{C}$ for $20 \mathrm{sec}$, and the amplification was finished with one cycle of $72^{\circ} \mathrm{C}$ for $10 \mathrm{~min}$. The PCR products after elution were cloned into a TOPO TA cloning vector (Invitrogen Life Technologies). Individual clones were sequenced using an automatic sequencer (ABI PRISM 377; Applied BioSystems).

$R N A$ isolation and semiquantitative reverse transcriptase PCR $(R T-P C R)$. Tissues from normally fertilized pigs and cloned pigs were collected and minced. Total-RNAs were extracted using TRIzol Reagent (Invitrogen Life Technologies) and used for the synthesis of a first-strand cDNA using a First-Strand cDNA Synthesis kit (Amersham Pharmacia Biotech) after heating to $60^{\circ} \mathrm{C}$ for $10 \mathrm{~min}$. The RT-PCR was semiquantitative in the linear portion of the exponential amplification for each gene. The oligonucleotide primers for the imprinted genes are shown in Table I.

Statistical analysis. The experiments were repeated at least 3 times with different sets of nuclear donor cells, ear tissue samples, in vitro fertilized or SCNT blastocysts (a total of 90 blastocysts). The data were subjected to one-way analysis of variance and the protected least significant different test using general linear models in a statistical analysis system (SAS, version 8.1 ) program. The data are presented as means \pm SD. Differences among the treatments were determined to be significant where P-value $<0.05$.

\section{Results}

We produced cloned pigs using two types of fetal fibroblasts (sPFFs and wPFFs, which differed by the day on which the fetuses were obtained) as nuclear donor cells (35). At birth, 


\section{A. Normal pigs}
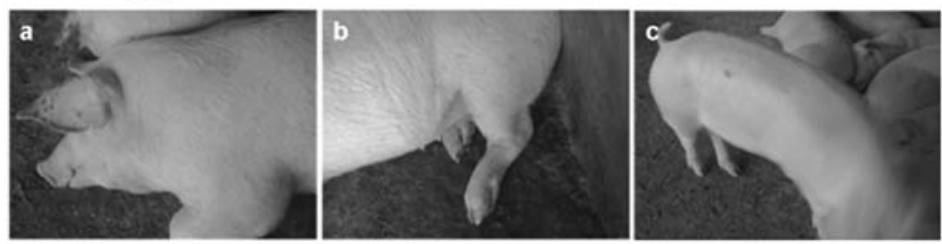

\section{B. Cloned pigs}
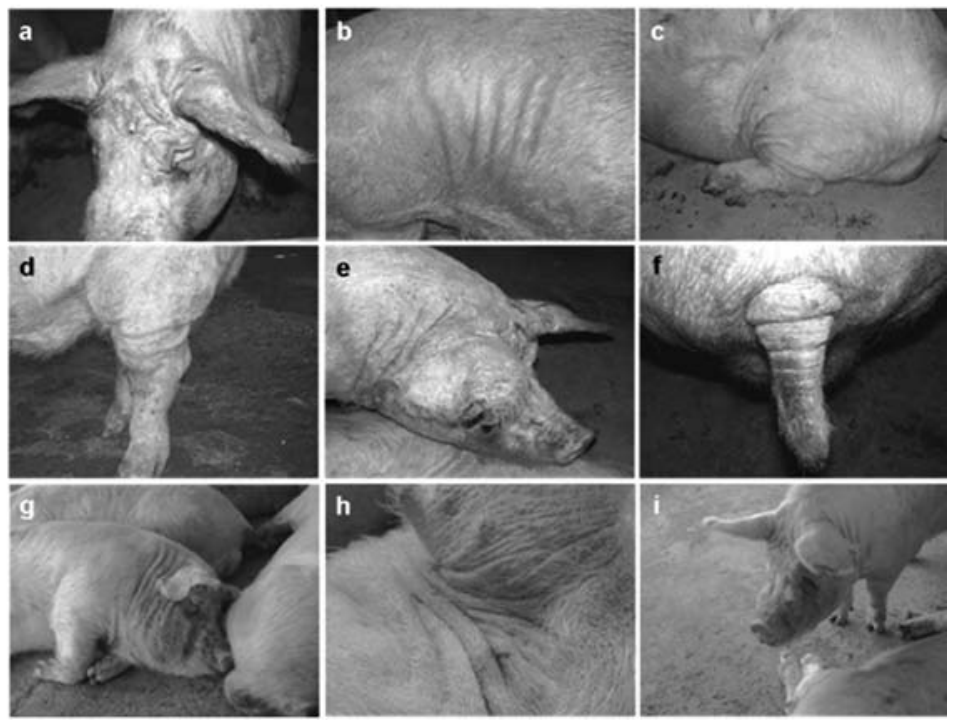

Figure 1. Phenotypic abnormalities found in 3 cloned pigs. To produce cloned piglets, we transferred the nuclei of donor cells to enucleated porcine oocytes. The normal cloned pigs were generated using wPFFs as donor cells and the wrinkled cloned-pigs were produced from sPFFs. Compared to age-matched normal (naturally fertilized) pigs, 3 pigs cloned by SCNT from sPFFs had many wrinkles on their bodies, including face, neck, legs and tail. (A) Age-matched normal pigs used as controls. At 2 years old, the normal pigs had smooth skin without wrinkles on the parts of the body that were wrinkled in the wrinkled cloned pigs. (B) Abnormal cloned pigs. To show distinct phenotypes, pictures taken (a-f) without or (g-i) with a flash are shown. (a, b, d, f and h) Also, the specific parts of the body are shown at high magnification to show the details of the specific abnormalities.

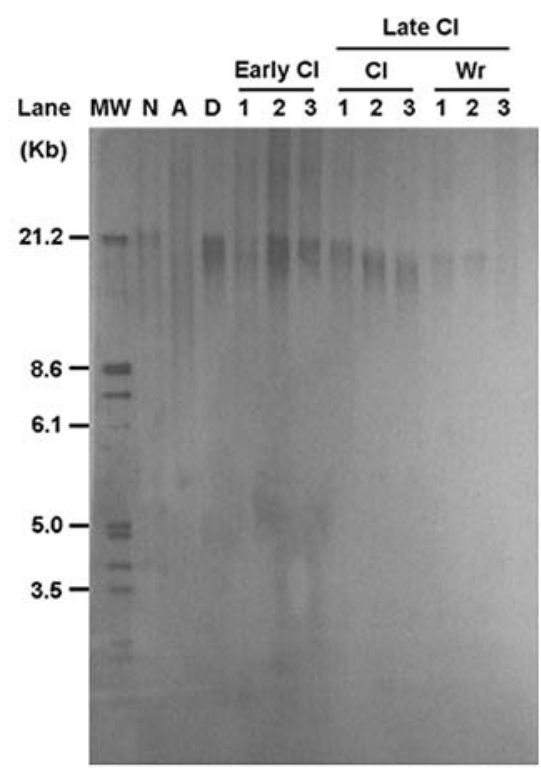

Figure 2. Analysis of telomere length in the wrinkled cloned pigs. Telomere lengths in age-matched normal pigs at 1 day ( $\mathrm{N}$, newborn) and 2 years $(\mathrm{A}$, adult) and donor fibroblasts isolated from a female fetus at 40 days of gestation (D, donor cells) were compared with those of the cloned pigs at two different stages, early (birth; lanes 1 to 3 ) and late (>2-years-old; lanes 4-9). The wrinkled cloned pigs had much shorter telomeres than normal cloned pigs. Telomere length was determined by mean terminal restriction fragment (TRF) length analysis. Molecular weight (MW) markers are displayed in $\mathrm{kb}$. Early $\mathrm{Cl}$, cloned pigs at birth; late $\mathrm{Cl}$, cloned pigs older than 2 years. the cloned pigs were healthy and were of normal weight, and the surface of skin and color appeared normal. At 2 years, however, we observed many wrinkles on the bodies of three cloned pigs the only ones obtained from sPFFs, which did not appear on age-matched normal pigs (Fig. 1B). The face around the nose and forehead was most wrinkled, the neck and ears were easily bent, and a line of wrinkles was present around the neck, ears, tail and legs. In contrast, age-matched normal pigs and normal cloned pigs showed normal smooth skin without wrinkles on these parts of the body (Fig. 1).

One of the important indications of senescence and successful reprogramming in SCNT animals is the telomere length. In our previous report (39), we measured telomere length in 15 cloned piglets, including the three wrinkled piglets and normal cloned pigs, and compared the lengths with those in donor somatic cells. The telomeres were longer in 1-day-old cloned piglets than in the nuclear donor cells and age-matched controls, suggesting that nuclear reprogramming resets the cellular age of donor cells after SCNT. Here, to determine whether the wrinkled phenotype is associated with the status of the genome or the age of the pigs, we compared the telomere lengths of the wrinkled and normal cloned pigs with those of age-matched normal pigs. First, telomere length was measured in adult pigs and newborn piglets to determine the normal reduction in length that occurs with biological and chronological aging. As expected, the 2-year-old adult pigs 
A. Cell

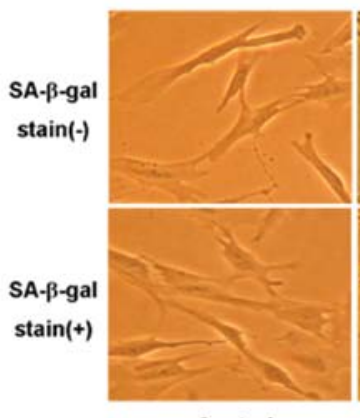

Control

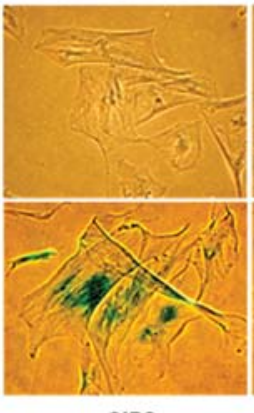

SIPS

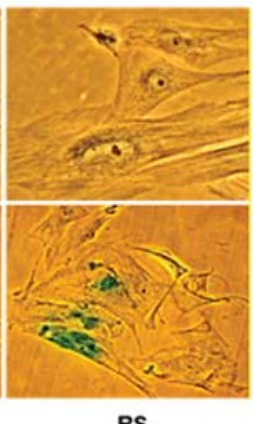

RS

B. Tissue

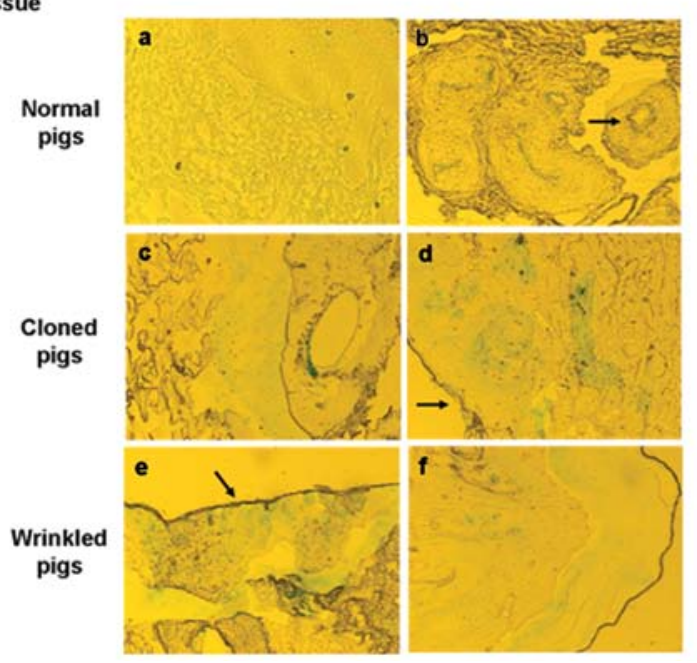

Figure 3. Senescence-associated $\beta$-galactosidase activity in cells and the tissues of cloned pigs. (A) SA- $\beta$-gal in cells. SA- $\beta$-gal stain (-) refers to unlabeled cells and SA- $\beta$-gal stain $(+)$ refers to cells labeled with SA- $\beta$-gal staining. Replicative senescence (RS) of pig fetal fibroblast cells (PFFs) was induced after long-term cell culture, and stress-induced premature senescence (SIPS) was induced by treatment with subcytotoxic doses of $\mathrm{HB}_{2 \mathrm{~B}} \mathrm{OB}_{2 \mathrm{~B}}$ for 5 days. Early-passage PFF cells were used as a control. The SA- $\beta$-gal-positive cells are shown in the SIPS and RS cells in the lower panel. The cells were photographed at x100 magnification. (B) SA- $\beta$-gal staining in the ear tissues of cloned pigs. Ear tissues were sectioned, stained for SA- $\beta$-gal and photographed at magnification $x 40$. All 6 cloned pigs were positive for SA- $\beta$-gal activity in the dermis and epidermis (c,d, normal cloned pigs; e,f, wrinkled cloned pigs). Keratinous layers were also positive for SA- $\beta$-gal in both kinds of cloned pigs (arrows in d,e). Keratinous layers contain many dead and aged cells. Moreover, SA- $\beta$-gal activity was always seen in the hair follicles and is frequently associated with sebaceous glands and eccrine glands and ducts. (a) However, no staining of SA- $\beta$-gal was observed in age-matched normal pigs, (arrow in b) except in the hair follicles stained as a positive control.

had shorter telomeres than the 1-day-old newborn piglets and the donor fibroblast cells. The telomeres were longer in the early cloned piglets (mean TRF length $=23.5 \pm 1.6 \mathrm{~kb}$ ) than in donor fetal fibroblasts (mean TRF length $=21.3 \pm 1.1 \mathrm{~kb}$; Fig. 2); however, telomere length decreased over time in both normal and wrinkled cloned pigs. Normal cloned pigs $>1.5$-years-old had a mean telomere length of $19.6 \pm 2.3 \mathrm{~kb}$, whereas wrinkled cloned pigs at the same age had shorter telomeres (mean TRF length $=18.7 \pm 0.6 \mathrm{~kb})(\mathrm{P}<0.05)$. Cloned pigs with or without wrinkles had shorter telomeres than age-matched normal pigs.

Along with telomere length analysis, we examined whether SA- $\beta$-gal activity, a biomarker of senescence, was present in our wrinkled cloned pigs. We first confirmed SA- $\beta$-gal staining in cells with replicative senescence (RS) or stress-induced prema-
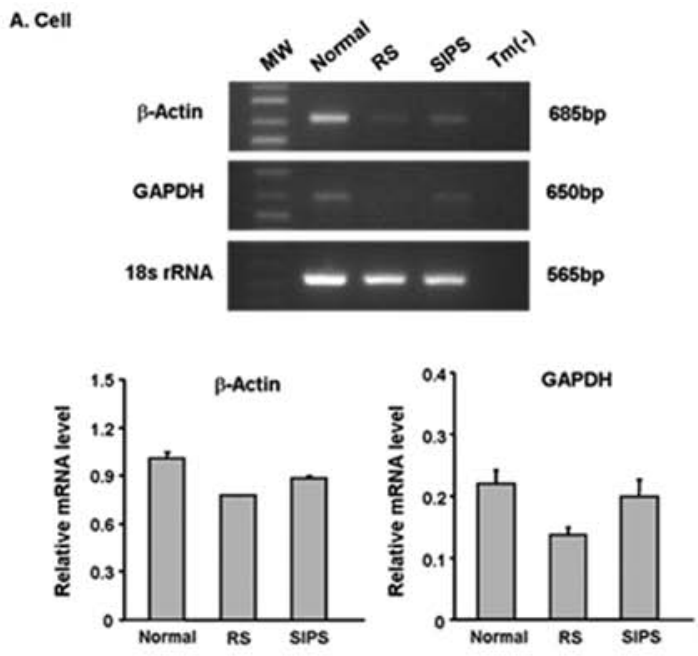

B. Tissues
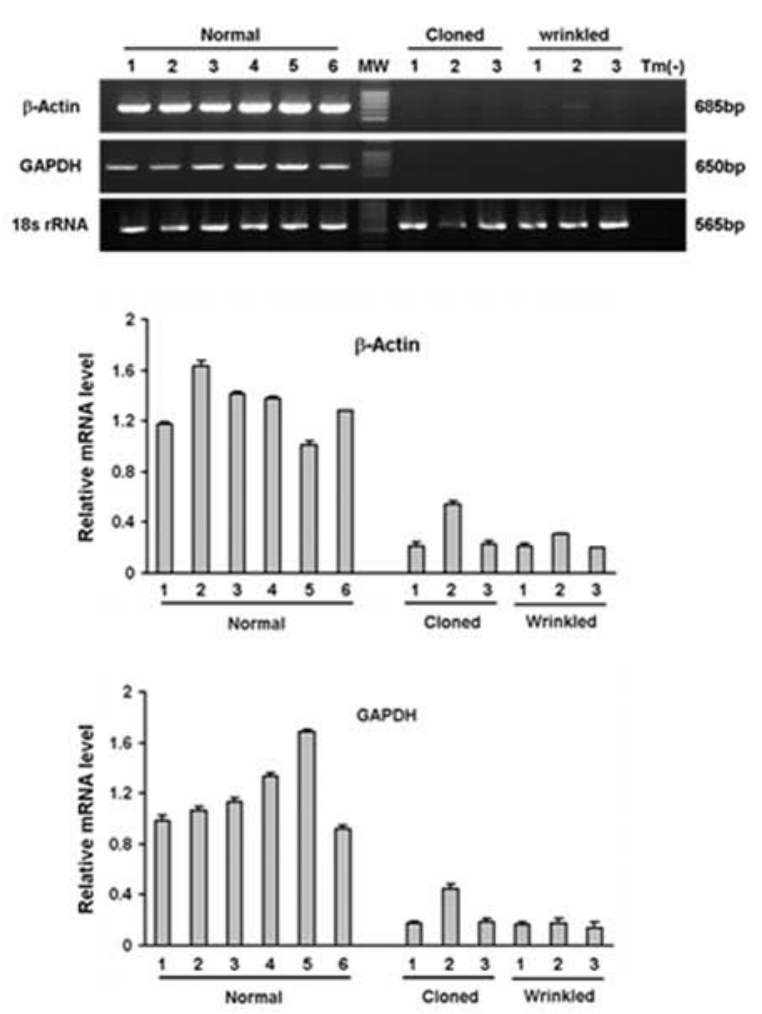

Figure 4. The expression of biomarkers for senescence in the abnormal cloned pigs. Relative mRNA levels of $\beta$-actin and GAPDH, which are biomarkers for senescence, were measured by RT-PCR. 18S rRNA was used as a reference for semiquantitative RT-PCR, because 18S rRNA is not differentially expressed with age. (A) Gene expression and quantification of $\beta$-actin and GAPDH in aged cells $(\mathrm{P}<0.05)$. Less $\beta$-actin mRNA and GAPDH mRNA was observed in the RS and SIPS cells than in the control cells. (B) Gene expression and quantification of $\beta$-actin and GAPDH in normal cloned pigs, wrinkled cloned pigs and normal age-matched control pigs $(\mathrm{P}<0.05)$. The normal cloned and wrinkled cloned pigs had significantly less $\beta$-actin mRNA than the age-matched pigs. Although there were individual differences in each group, GAPDH expression was also diminished in the cloned pigs. PFF, pig fetal fibroblasts used as control cells; RS, replicative senescence cells; SIPS, stress-induced premature senescence cells.

ture senescence (SIPS). The SIPS-associated morphology of PFFs was obtained by treating cells with $700 \mu \mathrm{M} \mathrm{H}_{2} \mathrm{O}_{2}$ for 5 days. For RS morphology, the cells were passaged every 7 days for $>15$ passages. The SIPS and RS cells had larger cell 


\title{
A. PRE-1
}

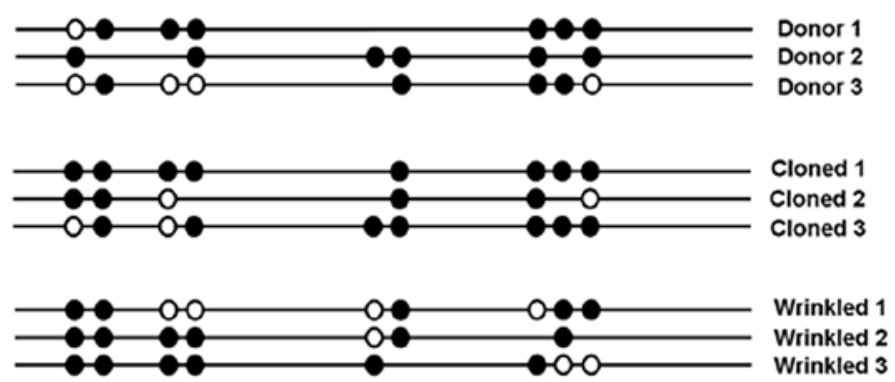

\author{
$78.6 \pm 25.8 \%$ \\ $(16 / 21)$ \\ $81.5 \pm 17.0 \%$ \\ (19/23) \\ $72.1 \pm 15.3 \%$ \\ $(17 / 24)$
}

\section{B. Satellite DNA}

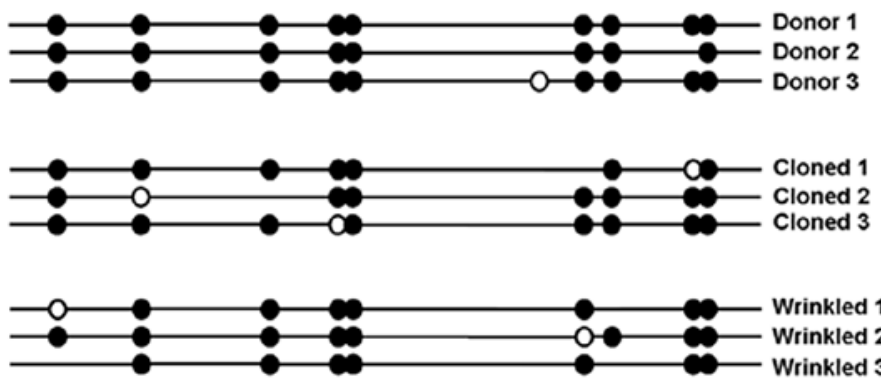

\section{$96.7 \pm 5.84 \%$ (26/27)

Figure 5. The methylation status of PRE-1 and satellite DNA sequence in the cloned pigs and the donor fibroblast cells. The genomic DNA was digested with HindIII and denatured with $0.3 \mathrm{~N} \mathrm{NaOH}$. Bisulfite modification was initiated by adding $5 \mathrm{M}$ sodium bisulfite and $10 \mathrm{mM}$ hydroquinone. PCR was performed for the amplification of the satellite region and the PRE-1 sequence. (A) Schematic diagram of amplified PRE-1 sequences showing the location of CpG dinucleotides (closed circles). The methylation status of each $\mathrm{CpG}$ site was scored by sequencing the PCR clones derived from bisulfite-treated genomic DNAs (B) Methylation profiles of $\mathrm{CpG}$ dinucleotides of satellite DNA sequences. Open and closed circles indicate unmethylated and methylated CpGs, respectively. Some $\mathrm{CpG}$ sites were absent from the satellite region in the cloned pigs and donor fibroblasts due to mutations and variation of satellite region in the particular copies of the satellite sequences. The numbers indicate the proportion of methylated $\mathrm{CpG}$ sites relative to the total number of $\mathrm{CpG}$ sites counted.

surfaces than the normal and early-passage PFFs (Fig. 3A). After 10 passages, the cell growth declined markedly (data not shown). The senescent pig fibroblasts expressed SA- $\beta$-Gal (shown as blue staining), while the early-passage cells did not show SA- $\beta$-Gal activity.

To examine whether senescent cells accumulate in vivo after SCNT, we stained ear tissues from the wrinkled and normal cloned pigs, as well as age-matched normal pigs, for SA- $\beta$-Gal activity when they were $>1.5$-years-old. We examined the sections for both the frequency and identity of the positive cells. The hair follicles and associated sebaceous glands and ducts were used as positive controls for SA- $\beta-$ Gal activity because these structures were stained with consistent frequency and intensity independent of age (Fig. 3Bb and c) (40). In the dermis and epidermis of both the wrinkled and normal cloned pigs, SA- $\beta$-Gal staining was sparsely and randomly distributed (Fig. 3Bc-f). The keratinous layers in the most peripheral region of sectioned tissue were also positive in both types of cloned pigs (Fig. 3Bd and e). In contrast, except for hair follicles, no blue precipitation was detected in the agematched normal pigs (Fig. 3Ba and b).

Expression levels of GAPDH and $\beta$-actin change with age in several cell and tissue types $(41,42)$; accordingly, they are not always a proper internal control for mRNA analyses regarding aging. We therefore used the level of $18 \mathrm{~S}$ rRNA as a reference and the mRNA levels of GAPDH and $\beta$-actin as biomarkers for senescence. We first performed semiquantitative RT-PCR with SIPS- and RS-associated cells. Less $\beta$-actin mRNA and GAPDH mRNA was observed in the RS and SIPS cells than in the control cells (Fig. 4A). We then determined the mRNA levels of these genes in the wrinkled and normal cloned pigs. Tissues from age-matched normal pigs were used as a control. The normal and wrinkled cloned pigs displayed significantly less $\beta$-actin mRNA than the age-matched pigs (Fig. 4B). GAPDH expression was also diminished in the cloned pigs. Although there were individual differences within each group, similar expression patterns were detected within the normal and wrinkled cloned groups.

We examined the methylation status of normal and wrinkled cloned pigs in order to determine whether the reprogramming process occurred during SCNT and whether the methylation pattern could contribute to the phenotypic abnormality. The pig euchromatic PRE-1 repetitive sequence, a subfamily of pig short interspersed element sequences, was chosen as a target for the methylation analysis. We characterized methylation patterns of the PRE-1 sequence using the bisulfite method. Bisulfite causes deamination of unmethylated cytosines to uridine, thereby allowing the discrimination of unmethylated and methylated cytosine residues through sequencing. Sixteen of the $21 \mathrm{CpG}$ sites $(78.6 \pm 25.8 \%)$ in the PRE-1 sequence were methylated in the donor cells (Fig. 5A). Hypomethylation was detected in the three wrinkled cloned pigs, where only $17 / 24$ sites $(72.1 \pm 15.3 \%)$ were methylated. Then we examined the methylation patterns of satellite DNA sequences in pigs. 

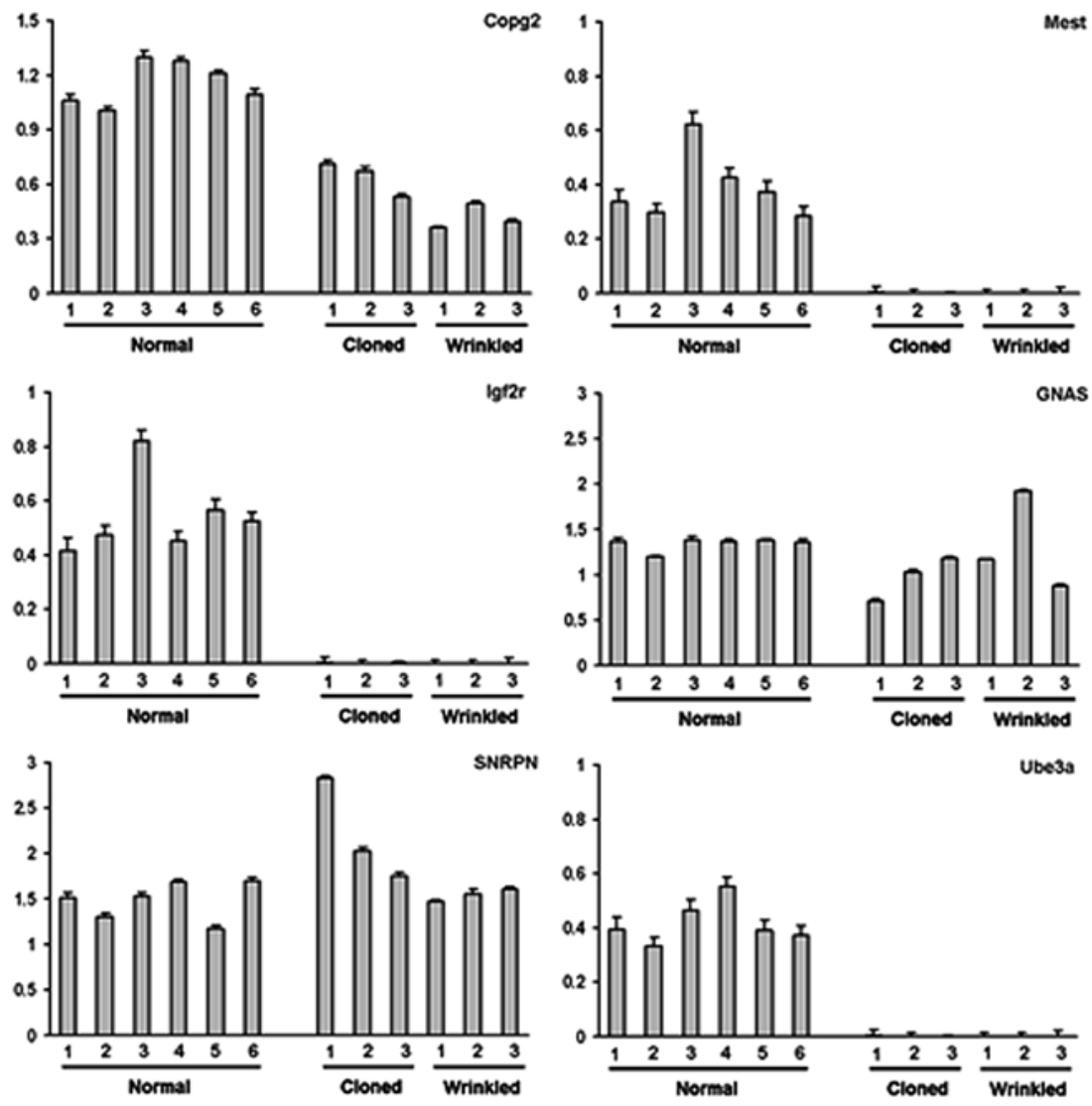

Figure 6. The mRNA levels of imprinted genes in the cloned pigs. Total-RNAs were isolated from ear tissues of the abnormal cloned pigs and donor fibroblast cells. A quantitative RT-PCR analysis showed a significant reduction in the mRNA levels of 6 imprinted genes (Copg2, Mest, Igf2R, GNAS, SNRPN and Ube3a). Except for Igf2R, none have previously been identified in pigs; they were obtained using homologous sequences in the mouse and human genes and confirmed by direct sequencing. The relative values were compared to the level of $18 \mathrm{~S}$ rRNA as a reference in at least 3 individual experiments $(\mathrm{P}<0.05)$. Four of the imprinted genes had considerably lower mRNA levels in the 2 cloned groups than in the normal age-matched pigs; however, the mRNA levels of SNRPN and GNAS were within the range of control levels. The transcripts of Igf2R, Mest and Ube3a appeared to be lower in both the wrinkled and normal cloned pigs than in the normal pigs.

A tiny difference in the methylation status of the satellite region was observed between the donor cells $(96.7 \pm 5.84 \%)$ and wrinkled cloned pigs $(92.1 \pm 6.9 \%)$. Since the donor cells used to produce normal cloned pigs were not available in this study, the methylation status in normal cloned pigs could not be directly compared with the donor cells. However, in normal cloned pigs, methylation was observed in $81.5 \pm 17.0 \%$ and $88.0 \pm 0.84 \%$ in both eucromatic PRE-1 repetitive sequences and centromeric satellite DNA. The status of the wrinkled cloned pigs was similar to that of the donor cells (Fig. 5).

Because parent-specific monoallelic expression of imprinted genes is critically important for normal embryo development (43), we determined the allelic pattern of imprinted genes in the wrinkled clones as well as in normal clones. However, few sequences of imprinted genes have been reported in the pig genome database. Therefore, we selected several imprinted genes whose DNA sequences are homologous between human and mouse. For PCR amplification, the primer set for each imprinted gene was designed from the consensus sequence and PCR products were directly sequenced. The PCR conditions, including annealing temperature, size of PCR products, primer sequences and the names of newly selected genes, are shown in Table I. Of the six imprinted genes, COPG2, SNRPN, MEST, GNAS1, UBE3A and IGF2R, all but IGF2R were newly identified in the pig. Using this information, relative transcript levels in the tissues of normal (control) pigs and the normal and wrinkled cloned pigs were estimated by quantitative RT-PCR $(\mathrm{P}<0.05)$. Four of the six imprinted genes had considerably reduced transcript levels in the two cloned groups compared to the normal age-matched pigs; however, the mRNA levels of SNRPN and GNAS were within the range of control levels. Although there were individual variations within each group, it appeared that there were lower amounts of Igf2R, Mest and Ube3a transcripts in the wrinkled and normal cloned pigs than in the normal pigs.

\section{Discussion}

We used SCNT to derive cloned pigs from two sets of donor cells, sPFFs and wPFFs. Although at birth the cloned pigs appeared normal, the pigs cloned from sPFFs started to show many deep wrinkles in their faces and bodies 2 years after birth. In a previous study, we reported on a cloned pig derived from fetal fibroblasts of an inbred miniature pig that had anal atresia (44). However, we could not determine the cause of this malformation with just one case. Many studies have reported that developmental aberrancies are due to fully unsuccessful reprogramming from somatic cell nuclei to embryonic genomes 
(20) or to the importance of donor cell selection and its preparation $(1,6,14,45-47)$. Here, we investigated whether the causes of the abnormal skin phenotype (body wrinkles) were derived from a genetic problem caused by donor specificity or from an epigenetic problem during reprogramming. First, we compared telomere length in wrinkled pigs with that of normal pigs and normal (unwrinkled) cloned pigs. In our previous studies, telomere length increased significantly in cloned pigs at birth. However, there was a dramatic shortening of the telomeres in the cloned pigs during growth and the time spent for SCNT (Fig. 2). These data suggest that aging may accelerate more quickly in the wrinkled cloned pigs and that, although there is no visible phenotype at early stages after birth, some error from the nuclear transfer is expressed during growth. Because telomere length is strongly influenced by many genetic and other factors, by itself it can be a poor indicator of aging or cell viability (48-50). To confirm that the wrinkled phenotype is a phenotype of aging, we further examined biomarkers for senescence (aging), including senescence-associated $\beta$-galactosidase (SA- $\beta$-gal) activity and the expression of GAPDH and $\beta$-actin. This specific type of the $\beta$-galactosidase enzyme is not expressed in young proliferating fibroblasts $(54,55)$. In our wrinkled cloned pigs and normal cloned pigs, positive SA- $\beta$-gal staining was clearly detected in the dermis and the epidermis. The outermost layer and hair follicles of sectioned tissue, known as the keratinous layers, were always positive for SA- $\beta$-gal in the age-matched normal pigs (Fig. 3Bb-e, black arrow). GAPDH and $\beta$-actin expression were also used as biomarkers for aging. Lowe et al (41) reported that GAPDH expression in skeletal muscles diminishes with age. In addition, Moe et al (42) suggested that GAPDH, $\beta$-actin and HPRT, but not $18 \mathrm{~S}$ rRNA, are differentially expressed at different developmental processes. The decreased mRNA levels of GAPDH and $\beta$-actin provide genetic evidence for senescence in our cloned pigs, in addition to the morphological evidence of the abnormal wrinkled phenotype. However, because these markers were observed in both kinds of cloned pigs, the appearance of these senescence markers are not due to abnormal aging that is expressed in wrinkling of the skin but are due to the SCNT procedures and genetic material from donor cells.

It is conceivable that an aberrant sequence of reprogramming events, especially DNA methylation, leads to developmental problems in cloned animals. Previously, Kang et al (26) reported that the methylation status of cloned donor genomes during cleavage was similar to that detected in fertilized counterparts (26). Interestingly, depending on their confirmed sequences, the methylation status of the PRE-1 and satellite DNA sequences was maintained in our wrinkled cloned pigs and showed few changes from those of the donor cells and complete reconstruction of genome status from donor. However, this is in contrast to observations in many previous studies. McKay et al (51) implicated aberrant DNA methylation in the pathogenesis of a number of diseases associated with aging, cancer and diseases of the cardiovascular and neurological systems (51). Accordingly, incomplete epigenetic changes in the donor genome alone might not be sufficient for the wrinkled phenotype of our cloned pigs and other complex factors may be required for this abnormality.

Given that the donor cells had identical methylation patterns, we examined whether the wrinkled phenotype of the cloned pigs was caused by abnormal imprinting. As shown in Fig. 6, the reduction in the mRNA levels of Mest, Igf2R and Ube3a may be associated with the developmental failure or abnormal phenotypes of the resultant cloned animals. In previous reports, mutation of imprinted genes resulted in fetal growth abnormalities in cloned animals and human patients $(52,53)$. Importantly, a substantial correlation was observed between the abnormal expression of any single imprinted gene and the degree of methylation in the promoter regions of the gene. However, the abnormalities observed in most clones result from the cumulative dysregulation of several imprinted genes (54). Consistent with the idea that a single imprinted gene could be insufficient to produce a substantial correlation with an abnormality, we showed that the repression of several imprinted genes does not make a critical contribution to the deep wrinkles in our cloned pigs. In conclusion, we showed that the abnormal wrinkled phenotype in our pigs cloned by SCNT was caused by a genetic abnormality of the donor cells, suggesting that the differentiation status of the donor cell affects the developmental potential of cloned animals. Therefore, although it is also important that donor cells be accurately reprogrammed to early-stage cells, the selection of good-quality donor cells is the ultimate challenge for successful cloning by SCNT.

\section{Acknowledgements}

This study was supported by a grant from the Next-Generation BioGreen 21 Program (no. PJ008323), Rural Development Administration, Republic of Korea.

\section{References}

1. Wilmut I, Schnieke AE, McWhir J, Kind AJ and Campbell KH: Viable offspring derived from fetal and adult mammalian cells. Nature 385: 810-813, 1997.

2. Campbell KH, McWhir J, Ritchie WA and Wilmut I: Sheep cloned by nuclear transfer from a cultured cell line. Nature 380 : 64-66, 1996.

3. Cibelli JB, Stice SL, Golueke PJ, et al: Cloned transgenic calves produced from nonquiescent fetal fibroblasts. Science 280 : 1256-1258, 1998.

4. Kato Y, Tani T, Sotomaru Y, et al: Eight calves cloned from somatic cells of a single adult. Science 282: 2095-2098, 1998.

5. Shiga K, Fujita T, Hirose K, Sasae Y and Nagai T: Production of calves by transfer of nuclei from cultured somatic cells obtained from Japanese black bulls. Theriogenology 52: 527-535, 1999.

6. Goto Y KK, Kobayashi S, Imai K, Shin-noh M, Tsujino T, Nakano T, Matsuda S, Nakane S and Kojima T: Birth of cloned calves derived from cultured oviductal epithelial cells of a dairy cow. Anim Sci J 70: 243-245, 1999.

7. Kubota C, Yamakuchi H, Todoroki J, et al: Six cloned calves produced from adult fibroblast cells after long-term culture. Proc Natl Acad Sci USA 97: 990-995, 2000.

8. Baguisi A, Behboodi E, Melican DT, et al: Production of goats by somatic cell nuclear transfer. Nat Biotechnol 17: 456-461, 1999.

9. Onishi A, Iwamoto M, Akita T, et al: Pig cloning by microinjection of fetal fibroblast nuclei. Science 289: 1188-1190, 2000.

10. Polejaeva IA, Chen SH, Vaught TD, et al: Cloned pigs produced by nuclear transfer from adult somatic cells. Nature 407: 86-90, 2000.

11. Betthauser J, Forsberg E, Augenstein M, et al: Production of cloned pigs from in vitro systems. Nat Biotechnol 18: 1055-1059, 2000.

12. Wakayama $\mathrm{T}$ and Yanagimachi R: Cloning of male mice from adult tail-tip cells. Nat Genet 22: 127-128, 1999.

13. Wakayama T, Shinkai Y, Tamashiro KL, et al: Cloning of mice to six generations. Nature 407: 318-319, 2000.

14. Wakayama T, Perry AC, Zuccotti M, Johnson KR and Yanagimachi R: Full-term development of mice from enucleated oocytes injected with cumulus cell nuclei. Nature 394: 369-374, 1998. 
15. Young LE, Sinclair KD and Wilmut I: Large offspring syndrome in cattle and sheep. Rev Reprod 3: 155-163, 1998.

16. Chavatte-Palmer P, Heyman Y and Renard JP: Cloning and associated physiopathology of gestation. Gynecol Obstet Fertil 28: 633-642, 2000.

17. Hill JR, Roussel AJ, Cibelli JB, et al: Clinical and pathologic features of cloned transgenic calves and fetuses (13 case studies) Theriogenology 51: 1451-1465, 1999.

18. Hill JR, Burghardt RC, Jones K, et al: Evidence for placental abnormality as the major cause of mortality in first-trimester somatic cell cloned bovine fetuses. Biol Reprod 63: 1787-1794, 2000.

19. Niemann $\mathrm{H}$ and Wrenzycki C: Alterations of expression of developmentally important genes in preimplantation bovine embryos by in vitro culture conditions: implications for subsequent development. Theriogenology 53: 21-34, 2000.

20. Rideout WM III, Eggan K and Jaenisch R: Nuclear cloning and epigenetic reprogramming of the genome. Science 293: 1093-1098, 2001.

21. Tian XC: Reprogramming of epigenetic inheritance by somatic cell nuclear transfer. Reprod Biomed Online 8: 501-508, 2004.

22. Gurdon JB and Colman A: The future of cloning. Nature 402: 743-746, 1999.

23. Bestor TH: Cytosine methylation and the unequal developmental potentials of the oocyte and sperm genomes. Am J Hum Genet 62: 1269-1273, 1998.

24. Lanza RP, Cibelli JB, Blackwell C, et al: Extension of cell life-span and telomere length in animals cloned from senescent somatic cells. Science 288: 665-669, 2000.

25. Reik W and Maher ER: Imprinting in clusters: lessons from Beckwith-Wiedemann syndrome. Trends Genet 13: 330-334 1997.

26. Kang YK, Koo DB, Park JS, et al: Typical demethylation events in cloned pig embryos. Clues on species-specific differences in epigenetic reprogramming of a cloned donor genome. J Bio Chem 276: 39980-39984, 2001

27. Dean W, Santos F, Stojkovic M, et al: Conservation of methylation reprogramming in mammalian development: aberrant reprogramming in cloned embryos. Proc Natl Acad Sci USA 98: 13734-13738, 2001.

28. Kang YK, Park JS, Koo DB, et al: Limited demethylation leaves mosaic-type methylation states in cloned bovine pre-implantation embryos. EMBO J 21: 1092-1100, 2002.

29. Tilghman SM: The sins of the fathers and mothers: genomic imprinting in mammalian development. Cell 96: 185-193, 1999.

30. Ferguson-Smith AC and Surani MA: Imprinting and the epigenetic asymmetry between parental genomes. Science 293 : 1086-1089, 2001

31. Vrana PB, Fossella JA, Matteson P, del Rio T, O'Neill MJ and Tilghman SM: Genetic and epigenetic incompatibilities underlie hybrid dysgenesis in Peromyscus. Nat Genet 25: 120-124, 2000

32. Young LE, Fernandes K, McEvoy TG, et al: Epigenetic change in IGF2R is associated with fetal overgrowth after sheep embryo culture. Nat Genet 27: 153-154, 2001.

33. Kato Y, Rideout WM, 3rd, Hilton K, Barton SC, Tsunoda Y and Surani MA: Developmental potential of mouse primordial germ cells. Development 126: 1823-1832, 1999.

34. Lee GS, Hyun SH, Kim HS, et al: Improvement of a porcine somatic cell nuclear transfer technique by optimizing donor cell and recipient oocyte preparations. Theriogenology 59: 1949-1957, 2003.

35. Hyun S, Lee G, Kim D, et al: Production of nuclear transferderived piglets using porcine fetal fibroblasts transfected with the enhanced green fluorescent protein. Biol Reprod 69: 10601068, 2003.
36. Lee GS, Kim HS, Hyun SH, et al: Production of transgenic cloned piglets from genetically transformed fetal fibroblasts selected by green fluorescent protein. Theriogenology 63: 973-991, 2005.

37. Kang YK, Koo DB, Park JS, et al: Aberrant methylation of donor genome in cloned bovine embryos. Nat Genet 28: 173-177, 2001.

38. Warnecke PM, Mann JR, Frommer M and Clark SJ: Bisulfite sequencing in preimplantation embryos: DNA methylation profile of the upstream region of the mouse imprinted H19 gene. Genomics 51: 182-190, 1998.

39. Jeon HY, Hyun SH,Lee GS, et al: The analysis of telomere length and telomerase activity in cloned pigs and cows. Mol Reprod Dev 71: 315-320, 2005

40. Dimri GP, Lee X, Basile G, et al: A biomarker that identifies senescent human cells in culture and in aging skin in vivo. Proc Natl Acad Sci USA 92: 9363-9367, 1995.

41. Lowe DA, Degens H, Chen KD and Alway SE: Glyceraldehyde3-phosphate dehydrogenase varies with age in glycolytic muscles of rats. J Gerontol A Biol Sci Med Sci 55: B160-B164, 2000.

42. Moe TK, Ziliang J, Barathi A and Beuerman RW: Differential expression of glyceraldehyde-3-phosphate dehydrogenase (GAPDH), beta actin and hypoxanthine phosphoribosyltransferase (HPRT) in postnatal rabbit sclera. Curr Eye Res 23: 44-50, 2001.

43. Reik W, Dean W and Walter J: Epigenetic reprogramming in mammalian development. Science 293: 1089-1093, 2001.

44. Lee GS, Kim HS, Lee SH, et al: Successful surgical correction of anal atresia in a transgenic cloned piglet. J Vet Sci 6: 243-245, 2005.

45. Uhm SJ, Chung HM, Kim C, et al: In vitro development of porcine enucleated oocytes reconstructed by the transfer of porcine fetal fibroblasts and cumulus cells. Theriogenology 54 : 559-570, 2000 .

46. Chesne P, Adenot PG, Viglietta C, Baratte M, Boulanger L and Renard JP: Cloned rabbits produced by nuclear transfer from adult somatic cells. Nat Biotechnol 20: 366-369, 2002.

47. Shin T, Kraemer D, Pryor J, et al: A cat cloned by nuclear transplantation. Nature 415: 859, 2002.

48. Blackburn EH: Telomere states and cell fates. Nature 408: 53-56, 2000.

49. Allsopp RC, Vaziri H, Patterson C, et al: Telomere length predicts replicative capacity of human fibroblasts. Proc Natl Acad Sci USA 89: 10114-10118, 1992.

50. Harley CB: Human ageing and telomeres. Ciba Found Symp 211: 129-144, 1997.

51. McKay JA, Williams EA and Mathers JC: Folate and DNA methylation during in utero development and aging. Biochem Soc Trans 32: 1006-1007, 2004.

52. Mann MR, Chung YG, Nolen LD, Verona RI, Latham KE and Bartolomei MS: Disruption of imprinted gene methylation and expression in cloned preimplantation stage mouse embryos. Biol Reprod 69: 902-914, 2003.

53. Yang L, Chavatte-Palmer P, Kubota C, et al: Expression of imprinted genes is aberrant in deceased newborn cloned calves and relatively normal in surviving adult clones. Mol Reprod Dev 71: 431-438, 2005

54. Inoue K, Kohda T, Lee J, et al: Faithful expression of imprinted genes in cloned mice. Science 295: 297, 2002.

55. Milner JM and Cawston TE: Matrix metalloproteinase knockout studies and the potential use of matrix metalloproteinase inhibitors in the rheumatic diseases. Curr Drug Targets Inflamm Allergy 4: 363-375, 2005. 